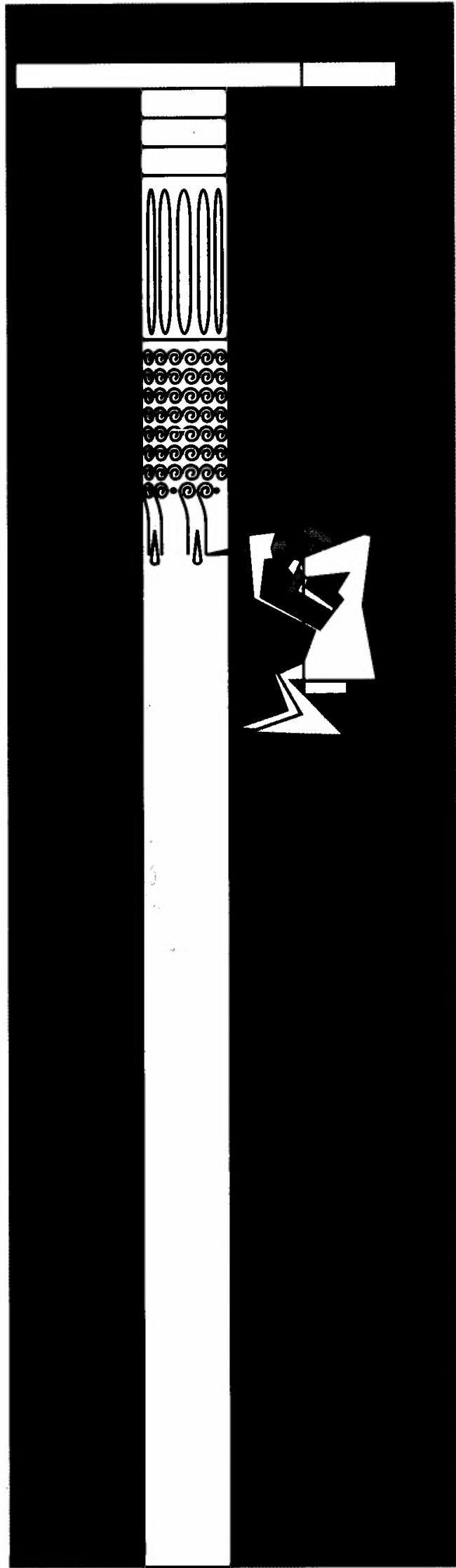

\title{
DESENVOLVENDO \\ A CRIATIVIDADE NAS ORGANIZAÇÕES O DESAFIO DA INOVAÇÃO
}

$\star$ Eunice Lima Soriano de Alencar

Um clima favorável à criatividade, aliado à prática intencional do processo de resolução criativa de problemas, facilita a mudança e a introdução bem-sucedida da inovação no contexto organizacional.

Favorable conditions and the practice to solve problems creatively make possible the change and the successful introduction of innovation in the organizational context.

PALAVRAS-CHAVE:

criatividade, inovação, organização, mudança.

KEY WORDS:

creativity, innovation, organization, change.

$\star$ Professora do Instifufo de Psicologia da Universidade de Brasília.

(rae@eaesp.fgvsp.br) Assinatura E-mail 
A criatividade está relacionada com os processos de pensamento que se associam com a imaginação, o insight, a invenção, a intuição, a inspiração, a iluminação e a originalidade. Embora seja muitas vezes considerada sinônimo de "inovação", observa-se que este último termo tem sido mais utilizado no contexto das organizações, enquanto o termo "criatividade" tem sido usado para falar de indivíduos e grupos de indivíduos. Dessa forma, a criatividade do indivíduo tem sido considerada o fator fundamental para a geração da inovação, de interesse da organização, constituindo a primeira o componente ideacional da inovação, enquanto esta englobaria a concretização e a aplicação das novas idéias ${ }^{1}$.

A criatividade tem também algo de mágico e misterioso, uma vez que as idéias criativas nem sempre ocorrem quando as desejamos ou as procuramos, mas costumam emergir inesperadamente, em momentos em que muitas vezes estamos distantes do problema.

A criatividade é um recurso valioso de que dispomos e que necessita ser mais cultivado, especialmente neste momento da história, em que a mudança e a incerteza parecem fazer parte inevitável de nossa vida. Esta é uma época caracterizada por aceleradas transformações tecnológicas, integração regional e mundial da produção e comercialização, universalização das comunicações, rápidas mudanças políticas e culturais etc. A competição empresarial e em outras áreas, nos níveis nacional e internacional, torna-se cada vez mais intensa. As soluções de que dispúnhamos para muitos problemas mostram-se hoje obsoletas, e novos desafios surgem a cada momento.

No contexto empresarial, por exemplo, a mudança está se tornando a regra e não a exceção. Novas demandas dos clientes, novos produtos, novas técnicas de produção e comercialização, novos processos de gerenciamento, novos mercados, sistemas mais eficientes de transporte e comunicação, entre outros, surgem a cada dia e cada vez mais rápido. A magnitude $e$ a velocidade dessas transformações estão a exigir novas formas de gerenciamento, que incluem decisões rápidas sobre fatos novos, para os quais não se pode contar com regras preestabelecidas. A par de medidas administrativas, como a descentralização do processo de decisão, este quadro está exigindo uma crescente capacidade criativa da parte das lideranças e de outros membros da força de trabalho das organizações.

Introduzir uma inovação nem sempre é algo simples, como se poderia imaginar à primeira vista. Isto porque a resistência à mudança é algo muito freqüente. Beverid$\mathrm{ge}^{2}$, biólogo e professor da Universidade de Cambridge, lembra, neste sentido, que a mente humana resiste a uma nova idéia, da mesma forma como o nosso organismo enfrenta um elemento estranho, rejeitandoa com igual intensidade. Observa-se uma série de fatores inibidores à aceitação de novas idéias ou propostas, como o hábito, a intolerância à ambigüidade, a baixa tolerância à mudança, o dogmatismo, o medo do desconhecido e a baixa propensão a correr riscos. Por esta razão, os dois grandes desafios a serem trabalhados no contexto organizacional são: como introduzir uma inovação e como facilitar o processo de adaptação dos indivíduos à mudança.

Ao contrário do que ocorre em alguns países mais avançados, com visão de futuro, no Brasil poucos têm procurado tirar proveito sistemático da criatividade. Uma das razões básicas para esse comportamento encontra-se no sistema educacional obsoleto. Observa-se que, por exemplo, embora seja a criatividade talvez o recurso mais precioso de nossa mente, ela não vem recebendo a atenção necessária em nossas escolas, e aqui nos referimos tanto ao primeiro e segundo graus quanto ao ensino universitário. Não há interesse por parte da escola em desenvolver a capacidade do aluno para pensar de uma maneira criativa e inovadora. Tampouco vem a escola estimulando nos alunos características como independência, disposição para aprender a partir dos próprios erros, persistência e autoconfiança, aliadas a uma atitude otimista e à coragem para correr riscos. Apesar de estarmos já vislumbrando um novo milênio, a nossa escola qualifica o indivíduo apenas parcialmente para a vida moderna, uma vez que o ensino continua praticamente nos mesmos moldes da
1. Na organização deste texto, foram utilizados como fontes principais o livro ALENCAR, E. M. L. S. Criatividade. Brasília: Editora da Universidade de Brasilla, 1993 e 0 artigo ALENCAR, E. M. L. S. 0 desafio da inovação. Razão, Lisboa, p. 22-23, abr. 1993,

2. BEVERIDGE, W. I. B. The art of scientific investigation. New York: Vintage Books, 1988. 
primeira metade do século, com ênfase na reprodução e memorização do conhecimento considerado relevante pelo professor. Dá ainda maior destaque à ignorância e à incompetência do aluno, deixando de lado o que cada um tem de melhor. Com isto, a criatividade reduz-se abaixo do nível das suas reais possibilidades, criando bloqueios, gerando insegurança, minando a autoconfiança e levando a um enorme desperdício de talento e de potencial criativo.

Ao examinar a questão da introdução da inovação no contexto organizacional, é necessário lembrar também que, além de alguns fatores da própria organização (empresa ou não), como características do clima psicológico predominante e possíveis barreiras internas à inovação, há também variáveis ligadas ao próprio indivíduo que podem facilitar ou emperrar, contribuir ou dificultar as mudanças que se fazem necessárias. As influências recíprocas entre organização e indivíduo são esquematizadas a seguir:

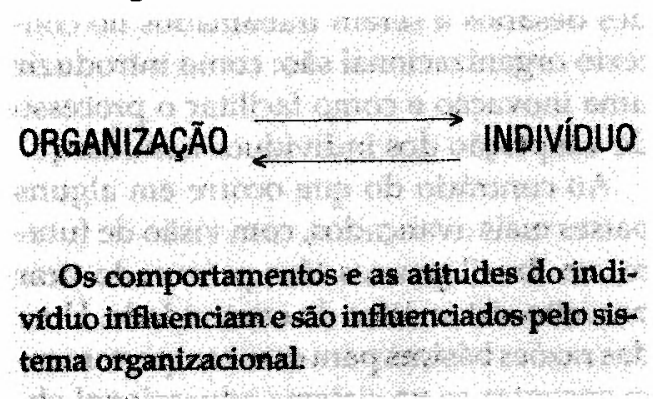

Além dessa influência recíproca, é necessário lembrar também que, em uma análise mais completa da questão, a par das características da organização e dos atributos e comportamentos dos seus membros, como motivação, autoconfiança e entusiasmo, há fatores de natureza extraorganizacional que também afetam o comportamento da instituição, como a competição com outras, similares, e o ambiente externo à organização, como o sistema político, as normas governamentais e os valores culturais.

Neste texto, daremos destaque a dois aspectos principais, a saber: características de um clima favorável à criatividade nas organizações e o processo de resolução criativa de problemas. Esse processo é um recurso poderoso, que pode ser utilizado na busca de soluções criativas para proble- mas enfrentados tanto pelo indivíduo como pelas organizações.

\section{CARACTERÍSTICAS DE UM CLIMA FAVORÁVEL À CRIATIVIDADE NAS ORGANIZAÇÕES}

O clima psicológico predominante na organização é um fator de fundamental importância para a promoção da criatividade e a geração de propostas inovadoras. Algumas características relativas a esse aspecto foram apresentadas por Van Gun$d^{3}{ }^{3}$ e estão relacionadas a seguir.

\section{Autonomia}

Grau em que se dá aos funcionários liberdade para inovar. Uma maneira de promover essa autonomia, por exemplo, posta em prática por algumas empresas, consiste em permitir que os funcionários da área de pesquisa passem parte do seu tempo, digamos $15 \%$, no desenvolvimento de projetos que nada têm a ver com suas obrigações, mas que eventualmente podem redundar em algo de interesse para a organização.

\section{Sistema de premiação dependente do} desempenho

Considera-se que há maior probabilidade de surgirem novas idéias quando os funcionários percebem que o sistema de premiação é justo e apropriado, e se baseia na competência e desempenho, em vez de se fundamentar na sorte ou nas relações pessoais do funcionário com os escalóes superiores da empresa.

\section{Apoio à criatividade}

Percepção, por parte dos funcionários, de que a organização está aberta a novas idéias e apóia possíveis mudanças que poderiam ser benéficas à instituição.

\section{Aceitação das diferenças e interesse pela} diversidade entre os membros

Tem-se observado que um maior número de propostas inovadoras ocorre quando há espaço para a divergência de pontos de vista e propostas. Por outro lado, a criatividade será certamente reprimida em um ambiente que não tolera as diferenças entre indivíduos. zational creativity and innovation. In: ISAKSEN, S. G. (ed.) Frontiers of creativity research. Buffalo: Bearly, 1987. 


\section{Envolvimento pessoal}

Inúmeras pesquisas têm apontado para a motivação intrínseca como um fator muito poderoso para a criatividade. Um indivíduo motivado, com alto grau de envolvimento, apresentará certamente alto nível de dedicação ao trabalho. Por outro lado, tem-se notado a presença dessa característica em empresas que dão apoio ao indivíduo, que reconhecem suas habilidades e esforço, levando-o a se sentir satisfeito no trabalho e motivado a se empenhar e dar o melhor de si.

\section{Apoio da direção}

Um clima criativo só ocorrerá caso haja apoio dos escalóes superiores da organização.

Outros fatores e características de um clima favorável na empresa à expressão da criatividade de seus funcionários são:

- motivar a produção de idéias;

- tolerar o fracasso, e encorajar a experimentação e o risco;

- não impedir e até facilitar a realização de um segundo trabalho;

- criar espaço para que os subordinados expressem suas opiniôes;

- fazer com que a pessoa sinta que se confia nela.

É notório que alguns princípios de administração e gerência têm sido observados em empresas que vêm se destacando nas áreas de inovação e criatividade. A literatura norte-americana ${ }^{4}$ cita, por exemplo, alguns desses princípios, que parecem facilitar o aproveitamento máximo dos recursos humanos, como os relacionados a seguir:

- insistir na liberdade, no local de trabalho, para que se possa perseguir idéias inovadoras;

- estruturas organizacional e política flexíveis, com ênfase na confiança e cooperação mútuas;

- estrutura organizacional e clima de trabalho em que prevaleça o respeito à dignidade e ao valor dos indivíduos, em que a iniciativa seja encorajada e as capacidades de cada um, desafiadas;

- estrutura organizacional que mantenha a autonomia e a flexibilidade, através da delegação de responsabilidade e autoridade.

Um dos recursos que temos utilizado em nossos seminários de criatividade na área organizacional, para se ter uma idéia do clima existente nas empresas, são as ana-

\section{A criatividade é um recurso valioso de que dispomos e que necessita ser mais cultivado especialmente neste momento da história, em que a mudança $e$ a incerteza parecem fazer parte inevitável de nossa vida.}

logias. Temos solicitado aos participantes desses seminários, após responderem a vários outros exercícios, para completarem a seguinte sentença: "A minha empresa é como ..."

Os exemplos apresentados a seguir ilustram algumas das respostas obtidas.

Minha empresa é como...

- Minha empresa é a extensão da minha casa.

- Minha empresa é o outro lado do meu lado.

- Minha empresa é como a menina dos meus olhos: eu sou o colírio.

- Minha empresa é como um quadro de esperança.

- Minha empresa é como um presídio: cada dia chega mais um.

- Minha empresa se parece com um trem-fantasma: quem está fora quer entrar, e quem está dentro quer sair.

- A empresa em que eu trabalho é como um palco, onde infelizmente muitos representam uma farsa.

- Minha empresa é como uma casa sem dono: muitos mandam e ninguém toma atitude alguma.

- Minha empresa é como um elefante: fácil de se ver, mas difícil de se mover.

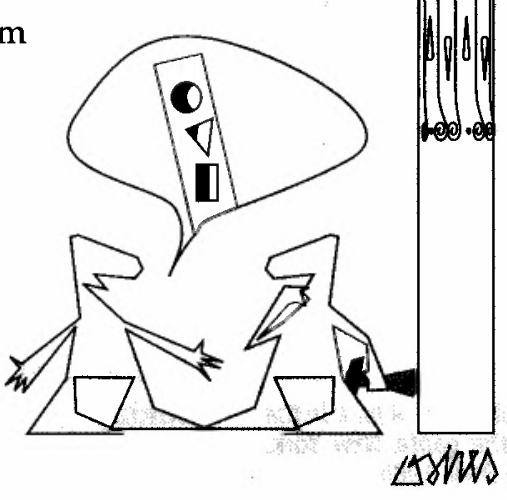

4. WHITING, B. G., SOLOMON, G. T. Key issues in creativity, innovation \& entropreneurship. Buffalo: Bearly, 1989. 
- Minha empresa é como cachaça: é ruim mas a gente gosta.

- A instituição onde eu trabalho é como uma chaleira que está prestes a explodir.

- A instituição onde eu trabalho é como uma balança: vive oscilando.

- A instituição onde eu trabalho é como uma colméia, em que existem as abelhas operárias, que trabalham sem cessar, e os zangões, cuja passagem é curta e voltada apenas para o próprio prazer.

Uma análise dessas respostas indica que para alguns o local de trabalho é visto de uma maneira positiva, ao passo que para outros o ambiente é percebido de maneira bastante adversa. Há ainda um terceiro grupo que identifica aspectos positivos e negativos presentes no seu local de trabalho.

\section{O PROCESSO DE RESOLUÇÃO CRIATIVA DE PROBLEMAS}

O processo de resolução criativa de problemas envolve três etapas distintas. A primeira caracteriza-se pelo levantamento do maior número possível de idéias e soluções para o problema que se deseja resolver. $\mathrm{Na}$ segunda etapa, examinam-se as diversas soluções propostas inicialmente, para se escolher então o melhor caminho. Finalmente, deve-se implementar, colocar em ação, a solução escolhida. Esta é a etapa final, que exige comportamentos bem distintos daqueles necessários nas etapas anteriores, de produção e avaliação de idéias.

Descreveremos aqui um modelo, inspirado em Von Oech ${ }^{5}$ e em Parnes ${ }^{6}$, que nos poderá orientar neste processo de busca e implementação da melhor solução para o problema que nos interessa resolver. Uma descriçāo mais completa poderá ser encontrada em Alencar?.

5. VON OECH, R. A kick in the seat of the pants. New York: Harper \& Row, 1986.

6. PARNES, S. J. Creative behavior guidebook. New York: Scribner, 1967.

7. ALENCAR, E. M. L. S. Como desenvolver o potencial criador. Petropolis: Vozes, 1991. turá-lo, vendo-o sob um novo enfoque, ângulo ou ponto de vista. É comum ficarmos cegos a alguns aspectos da questão ou presos a soluções que se mostram inadequadas, mas das quais somos incapazes de nos libertar. Daí a importância de cultivarmos as características de um bom explorador de idéias.

Um bom explorador procura novos fatos e informações, adquirindo e utilizando a bagagem de conhecimentos necessária para a busca de novas respostas. Assim como aquele que busca um veio de ouro numa floresta não deve seguir apenas trilhas já abertas, pois elas provavelmente não levarão ao objetivo almejado, o explorador de idéias deve aventurar-se por vários caminhos, examinando o maior número de possibilidades que possam levá-lo a uma solução mais adequada. Deve fazer uso de sua curiosidade, não se atemorizando em investigar o maior número possível de informações, fatos e impressões.

Deve usar os sentidos para observar, prestando atenção a detalhes que talvez contenham as pistas que levarão à solução adequada de um problema. E, assim como procede um fotógrafo profissional, que tira dezenas de fotos antes de escolher as melhores para uma dada reportagem, também o nosso explorador deve buscar muitas idéias. Para tal, a melhor estratégia é conciliar o domínio do conhecimento com a aplicação de técnicas adequadas, como o brainstorming ("tempestade de idéias") ou a listagem de atributos, as quais favorecem a emergência de muitas respostas.

\section{Segunda etapa: a busca da melhor solução}

Após produzir muitas respostas e soluções, deve-se agir como um juiz, o qual, diante de muitas idéias, precisa se decidir pela melhor. Esta não é, porém, uma tarefa simples, pois nem sempre a resposta que nos parece correta ou adequada é a melhor para o problema em causa.

Para facilitar a avaliação de idéias, alguns estudiosos, como Parnes, sugerem que o processo de avaliação seja feito de uma forma sistemática, após a pessoa dispor de um grande número de possíveis soluções, considerando-se as seguintes etapas: primeiramente, deve-se selecionar al- 
guns critérios ou padrões de julgamento (como custo, utilidade, beleza, tempo etc.). Estes poderão ser propostos utilizando-se o princípio de julgamento adiado, ou seja, levantam-se inicialmente muitos critérios, escolhendo-se posteriormente os mais apropriados. Após elaborar uma lista de critérios, cada idéia ou solução é, então, julgada com relação a cada um deles, utilizando-se uma escala de três pontos, onde " 1 " seria insatisfatório, " 2 " razoável e " 3 " satisfatório. Após serem avaliadas as idéias com o primeiro critério, são elas então novamente julgadas, utilizando-se o segundo critério, e assim sucessivamente. Concluída a avaliação, selecionam-se as soluções com o maior número de pontos.

Algumas perguntas deveriam também ser respondidas nesta etapa, antes de se dar início à etapa de implementação de idéias. Algumas delas são:

- É este o momento para se colocar a idéia em prática?

- Vale a pena investir nesta idéia?

- Tenho os recursos necessários para implementá-la?

- Quais são as chances de sucesso, caso a idéia seja colocada em prática?

Terceira etapa: a implementação da idéia O processo de implementação de uma nova idéia ou solução pode encontrar barreiras e dificuldades. Isto porque a mudança e a inovação são geralmente vistas como ameaçadoras. Também não é raro haver uma reação negativa diante de qualquer empreendimento que diverge do comum, do vulgar e do conhecido. A rejeição das novas idéias tem sido regra e não exceção em muitos contextos. Por esta razão, para que uma idéia não morra, é muitas vezes necessário lutar por ela e não se deixar vencer pelos inúmeros obstáculos de que a sociedade dispóe para matar uma idéia, $e$ que se refletem com freqüência nos comentários apresentados a seguir: "nunca fizemos isso antes"; "não estamos preparados para isso"; "alguém já tentou isso antes?"; "temos ido muito bem sem isso".

É necessário também tomar consciência dos bloqueios internos que nos impedem de colocar uma nova idéia em prática e que se traduzem por comentários do gênero: "tenho medo de errar"; "não sou capaz"; "tenho medo de não dar certo"; ou "tenho medo de ser criticado".

Por esta razão, é necessário cultivar as qualidades de um guerreiro que se empenha na defesa e implementação da sua pró-

\section{A inovação é forçosamente um desafio. Na sociedade atual, é também uma necessidade. O que importa é promover condições para o desenvolvimento das potencialidades presentes em todo ser humano e despertar a consciência das organizações para as potencialidades de seus recursos humanos.}

pria idéia e que não se deixa abater facilmente diante dos possíveis obstáculos. A habilidade para negociar e vender a nova idéia ou solução pode desempenhar um papel decisivo em sua aceitação.

Para implementar a solução, é também recomendável que se organize um plano de ação em que sejam respondidas as seguintes questões:

- Quem participará no processo de colocação da idéia em prática?

- Quando ela será implementada?

- Onde?

- De que forma?

Para finalizar, destacamos que a inovação é forçosamente um desafio. Na sociedade atual, é também uma necessidade. $O$ que importa é promover condições para o desenvolvimento das potencialidades presentes em todo ser humano e despertar a consciência das organizações para as potencialidades de seus recursos humanos, que na maioria das vezes não têm sido devidamente reconhecidas e aproveitadas. $\square$

0950601 